\title{
Analisis Hubungan Kausalitas Antara Jumlah Uang Beredar, Bi Rate dan Inflasi di Indonesia Tahun 2010-2016
}

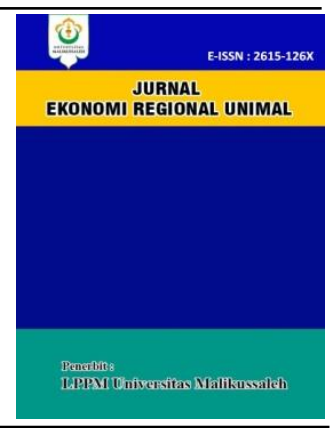

\author{
Khairil Anwar ${ }^{* a}$, Ansari ${ }^{* b}$ \\ *Fakultas Ekonomi dan Bisnis Universitas Malikussaleh \\ a Corresponding author: khairil.anwar.semsi@gmail.com \\ b ansariekp@gmail.com
}

A R T I CLE I N F O RMA T I O N

Keywords:

Money Supply, BI Rate, Inflation, Granger Causality.

\section{A B S T R A C T}

The purpose of this study is to know the causality relationship between the money supply, BI Rate, and inflation. The data used in this study is the secondary data in the form of time series from January 2010 to December 2016 in Indonesia. Granger Causality method uses to analyze the data. The research shows that there is no causal relationship between the money supply with BI Rate. Furthermore, there is no causal relationship between money supply and inflation. Then there is a one-way relationship between BI Rate and inflation.

\section{PENDAHULUAN}

Bank sentral mempunyai fungsi dan peran yang stategis dalam mendukung perkembangan perekonomian, serta operasi dan kesehatan perbankan, yang pada gilirannya akan mempengaruhi tidak hanya perkembangan sektor keuangan, tetapi juga pertumbuhan ekonomi, inflasi dan kesejahtraan masyarakat. Tugas bank sentral pada umumnya mencakup perumusan dan pelaksanaan kebijakan moneter, pengaturan dan pengawasan perbankan, dan pengaturan dan pelaksanaan sistem pembayaran (Bank Indonesia, 2004).

Menurut (Alvyonita, 2012), selain menetapkan suku bunga bank umum, Bank Indonesia juga menetepkan suku bunganya sendiri (BI Rate). BI Rate merupakan suku bunga acuan perbankan di Indonesia dan juga berfungsi sebagai reference rate dalam mengendalikan kebijakan moneter dalam mengatasi inflasi di Indonesia.
Dari penjelasan di atas dapat disimpulkan bahwa apabila uang beredar tinggi, cara mengstabilkannya adalah Bank Indonesia akan melakukan kebijakan moneter melalui BI Ratenya dengan cara meningkatkan persentase BI rate di Indonesia. Dengan meningkatnya persentase BI rate maka JUB akan menurun karena masyarakat akan lebih cenderung untuk menabung ke bank dan masyarakat akan mendapatkan keuntungan pada akhirnya inflasi akibat peningkatan JUB dimasyarakat juga akan menurun. Oleh karena itu, antara JUB, BI rate dan inflasi saling berhubungan satu sama lain dan perkembangannya pada tiga tahun terakhir dapat dilihat pada Tabel 1.1 berikut.

Tabel 1

Perkembangan JUB, BI Rate dan inflasi di Indonesia Tahun 2014-2016

\begin{tabular}{|c|c|c|c|}
\hline Tahun & JUB (Milyar) & $\begin{array}{c}\text { BI } \\
\text { Rate(\%) }\end{array}$ & Inflasi(\%) \\
\hline 2014 & Rp.942.221,34 & 7.75 & 8.36 \\
\hline 2015 & Rp.105.5285,07 & 7.50 & 3.35 \\
\hline 2016 & Rp.1.237.642,57 & 3.02 & 3.02 \\
\hline
\end{tabular}

Sumber: www.bi.go.id, 2017 
Dari teori tersebut berarti BI rate berhubunhan positif dengan JUB. BI Rate di Indonesia pada Tabel $1.1 \mathrm{di}$ atas, dapat dilihat bahwa perkembangan BI Rate di Indonesia tiga tahun terakhir mengalami penurunan. Pada tahun 2014 BI Rate sebesar 7.75\%. selanjutnya pada tahun 2015 menurun menjadi 7.50\% kemudian pada tahun 2016 junga mengalami penurunan hingga $3.02 \%$.

Dari data di atas, terjadi permasalahan yang bertentangan dengan teori yang telah dijelaskan di atas yaitu fenomena yang terjadi pada tahun 2016 . Dimana JUB pada tahun tersebut mengalami peningkatan sedangkan $\mathrm{BI}$ rate mengalami penurunan berarti fenomen tersebut berhubungan negatif. Sedangkan hubungan JUB dengan BI Rate menurut teori adalah berhubungan positif. Oleh karena itu, maka fenomena yang terjadi pada tahun 2016 tidak sesuai dengan teori yang di kemukakan.

Berdasarkan data dalam Tabel 1.1 terdapat fenomena-fenomena antara JUB, BI rate dan inflasi yaitu pada tahun 2016 JUB meningkat, BI rate menurun sedangkan inflasi juga mengalami penurunan pada tahun tersebut. Oleh karena itu, fenomena tersebut tidak sesuai dengan teori yang di temukakan di atas. Seharusnya apabilah JUB tinggi maka BI rate juga tinggi agar JUB dimasyarakat berkurang. Sedangkan tingkat inflasi pada tahun tersebut sangat rendah. Oleh karena itu peneliti mengambil keputusan berdasrkan teori diatas dan fenomena data yang diperoleh maka pada tahun tersebut tidak sesuai dengan teori. Selanjutnya disaat BI rate ditingkatkan pada tahun 2014 dengan kebijakan untuk mangurangi JUB pada tahun 2014 dan mengharapkan agar tingkat inflasi rendah. Tetapi pada kenyataannya tingkat inflasi justru meningkat pada tahun tersebut.

Berdasarkan fenomena-fenomena data dan uraian di atas maka penulis tertarik untuk meneliti lebih lanjut mengenai analisis hubungan kausalitas antara JUB, BI rate dan inflasi di indonesia tahun 2010-2016.

Dimana penelitian ini bertujuan untuk mengetahui ada tidaknya hubungan kausalitas antara JUB dengan BI Rate di Indonesia Periode 2010-2016 dan mengetahui ada tidaknya hubungan kausalitas antara JUB dengan inflasi di Indonesia
Periode 2010-2016 dan selanjutnya mengetahui ada tidaknya hubungan kausalitas antara BI Rate dengan inflasi di Indonesia Periode 2010-2016

\section{TINJAUAN TEORITIS Jumlah Uang Beredar (JUB)}

Di Indonesia dan seluruh negara di dunia pasti mengenal yang namanya uang karena sudah dikenal seluruh masyarakat di dunia. Uang merupakan alat tukar dan alat pembayaran yang sah untuk memudahkan pelaku ekonomi dalam transaksi baik antar negara maupun transaksi didalam negara itu sendiri. JUB di masyakat harus dijaga kestabilannya karena dapat mempengaruhi perekonomian. Dalam penelitian ini JUB yang dibahas adalah JUB dalam arti sempit (M1) yaitu uang kartal (kertas dan logam) yang berada dilingkungan masyarakat dan ditambah dengan uang giral pada bank umum dalam bentuk deposito. JUB adalah jumlah mata uang (uang kertas dan logam / uang kartal) yang di terbitkan oleh bank sentral, yang dipegang oleh masyarakat dan termasuk uang kartal yang dipegang oleh bank termasuk dalam cadangan (Silvanita, 2009). Oleh karena itu, maka JUB dalam arti sempit (M1) dapat disimpulkan yaitu total jumlah uang kertas dan logam yang beredar di masyarakat dan bankumum.

Penyebab JUB disuatu negara berfluktuasi yaitu turun naik karena disebabkan beberapa faktor yang berhubungan dengan masalah ekonomi makro. Faktor-faktor tersebut menurut Febrian (2014 dalam Mursalin, 2016), yaitu: 1). Pendapatan masyarakat, pendapatan masyarakat akan mempengaruhi peredaran uang. Apabila jumlah pendapatan yang diperoleh masyarakat makin tinggi maka JUB di masyarakat juga semakit tinggi. Sebaliknya, jika pendapatan masyarakat semakin rendah, maka jumlah uang yang beredar juga semakin sedikit. 2). Jumlah penduduk, jumlah penduduk memang menentukan cepatnya jumlah uang yang beredar pada masyarakat yang jumlah penduduknya padat. Jumlah uang yang berdar akan semakin banyak. Berbeda halnya dengan masyarakat yang jumlah penduduknya sedikit, jumlah uang yang beredar juga sedikit. 3). BI Rate, semakin tinggi BI Rate maka JUB di masyarakat semakin sedikit, hal ini 
dikarenakan masyarakat lebih senang menyimpan uangnya di bank. Dan sebaliknya, jika BI Rate turun, maka JUB semakin banyak, hal ini disebabkan masyarakat lebih suka untuk konsumsi/berinvestasi dari pada menabung sebab bunga di bank sedikit. 4). Harga barang, apabila harga barang naik maka JUB semakin banyak karena orang lebih banyak membutuhkan uang untuk membeli barang. 5). Selera masyarakat, selera masyarakat dapat mempengaruhi JUB dimasyarakat. Ketika selerah masyarakat terhadap suatu barang tertentu tinggi maka JUB akan semakin banyak. Begitu pula sebaliknya.

\section{Suku Bunga (BI Rate)}

Tujuan Bank Indonesia melakukan kebijakan moneter adalah untuk mengatur dan mengendalikan perekonomian. Salah satu hak dan kewajiban BI adalah menetapkan suku bunga Bank Indonesia atau sering dikenal denga BI rate. BI Rate Bank Indonesia merupakan acuan bank umum dan lembaga keuangan lainnya atau sering disebut dengan BI rate. Menurut Setioeti (2014), BI Rate adalah suku bunga kebijakan yang mencerminkan sikap atau stance kebijakan moneter yang ditetapkan oleh bank Indonesia dan diumumkan kepada publik. Secara sederhana suku bunga adalah harga uang. Suku bunga akan naik apabila jumlah uang sedikit dan permintaan terhadapnya besar. Sebaliknya, suku bunga akan turun bila mana jumlah uang besar dan permintaan terhadapnya sedikit (Hidayat, 2013). BI Rate Merupakan nilai uang yang menghubungkan masa kekarang dengan masa yang akan mendatang akibat adanya inflasi.

Terdapat beberapa faktor yang mengakibatkan BI Rate selalu berfluktuasi atau Bank Indonesia (BI) menaikkan dan menurunkan BI Ratenya. Berdasarkan teori likuiditsa diatas maka dapat diambul kesimpulan bahwa faktorfaktor yang menentukan BI Rate yaitu: 1). Jumlah penawaran uang (money supply) yaitu jumlah uang yang ada dalam perekonomian dan digunakan oleh masyarakat untuk memper oleh barang dan jasa. Oleh karena itu, apabilah jumlah penawaran uang (uang beredar) dimasyarakat meningkat maka akan mengakibatkan harga barang-barang dan jasa-jasa akan meningkat sehingga terjadi inflasi. Cara mengatasi masalah tersebut adalah BI membuat kebijakan agar jumlah penawaran uang menurun dimasyarakat dengan cara menaikan BI Rate. 2). Jumlah permintaan uang (money demand) adalah keinginan masyarakat untuk memperoleh uang untuk digunakan bertransaksi, disimpan dan digunakan untuk membiayai kebutuhan sehari-hari dan kebutuhan masa mendatang. Oleh sebab itu BI Rate di turunkan oleh Bank Indonesia agar masyarakat tidak lagi mau menabung di bank karena tidak mendapatkan keuntunga dari bunga tabungannya dan masyarakat akan lebih dominan untuk membuka usaha sendiri karena lebih menguntungkan.

\section{Inflasi}

Inflasi salah satu fariabel ekonomi makro yang selalu terjadi disetiap negara. Tingkat inflasi bisa berdampak baik dan buruk dalam perekonomian suatu negara. Inflasi yang tidak diinginkan adalah infalasi berat dan hiper inflasi karena infalsi tersebut bisa berdampak buruk terhadap perekonomian. Sedangkan inflasi rendah dan sedang tidak berdamak buruk terhadap perekonomian bahkan bisa meningkatkan perekonomian suatu negara. Menurut (Qizfir, 2015) inflasi adalah kecendrungan harga-harga untuk naik secara terus-menerus dan umum. Kenaikan harga dari satu dua barang saja tidak bisa disebut dengan inflasi, kecuali kenaikan tersebut meluas kepada barang-barang lainnya. Penyebab terjadinya inflasi yaitu meningkatnya JUB dimasyarakat sehingga mengakibatkat permintaan terhadap faktor produksi meningkat maka harga juga akan meningkat. Selanjutnya disebabkan oleh kurangnya barang yang diproduksi sehingga dengan langkanya suatu barang maka harga akan tinggi. Selanjutnya diakibatkan oleh kenaikan upah tenaga kerja.

Terdapat beberapa macam bentuk inflasi yang terjadi disetiap negara Indonesia maupun negara-negara tetangga. Tinggi rendahnya inflasi yang terjadi disuatu negara dapat ditentukan oleh kegiatan perekonomian secara makro dan kebijakan pemerintah di negara tersebut. Inflasi tidak semua berdampak buruk terhadap perekonomian karena kenaikan harga-harga juga sangat diperlukan untuk mempercepat roda 
perekonomian. Oleh karena itu, terdapat beberapa macam inflasi (Qizfir, 2015) yaitu: 1). Inflasi ringan (dibawah $10 \%$ per tahun). 2). Inflasi sedang (10\%-30\% per tahun). 3). Inflasi berat (30\%-100\% per tahun). 4). Hiper inflasi (100\%).

\section{METODE PENELITIAN Lokasi Dan Objek Penelitian}

Penelitian ini dilakukan di Indonesia dan penelitian ini hanya dibatasi pada variabel JUB (JUB) dalam arti sempit (M1), BI Rate (BI rate) dan inflasi dari priode januari 2010 sampai dengan desember 2016 di Indonesia.

\section{Sumber Data}

Objek penelitian ini adalah JUB, BI Rate dan inflasi di Indonesia periode januari 2010 sampai dengan desember 2016. Dalam penelitian ini data yang digunakan adalah data skunder dalam bentuk time series (runtun waktu) selama kurun waktu januari 2010 sampai dengan desember 2016 di Indonesia.

\section{Metode Analisis Data}

Untuk menganalisis data dalam penelitian ini adalah dengan menggunakan aplikasi Eviews 9 yaitu:

\section{a. Uji Stasionaritas (Unit Root Test)}

Uji ini digunakan untuk mengetahui apakah data memiliki unit root atau tidak serta untuk mengetahui derajat stasioneritas data. Uji stasioneritas data dilakukan untuk melihat apakah data terintegrasi pada ordo yang sama atau tidak. Pengujian stasioneritas dalam penelitian ini dilakukan dengan menggunakan uji Augmented Dickey-Fuller (ADF) dan Phillips-Perron (PP). Pengujian ini dilakukan dengan membandingkan antara t-statistic dan critical value $(1 \%, 5 \%, 10 \%)$ yang dihasilkan, apabila t-statistic lebih besar daripada critical value maka H0 di tolak, yang berarti data adalah stasioner (Oktavia dan Amri, 2017:169).

Jika hasil uji stasioneritas berdasarkan uji ADF diperoleh data seluruh variabel belum stasioner pada level, maka untuk memperoleh data yang stasioner dapat dilakukan dengan cara differencing data yaitu dengan mengurangi data tersebut dengan data periode sebelumnya, sehingga akan diperoleh data dalam bentuk first difference.

\section{b. Penentuan panjang $\mathrm{Lag}$}

Dalam menggunakan metode Granger Causality, juga dilakukan penentuan panjang lag yang ada dalam variabel penelitian. Jika panjang lag yang digunakan terlalu banyak lag dalam model, maka dapat mengurangi kemampuan hipotesis nol (H0) ditolak karena tambahan parameter yang terlalu banyak akan mengurangi derajat bebas (Maria Alvyonita, 2012:624). Penentuan jumlah lag dalam metode Vector Auto Regression (VAR) ditentukan pada kriteria informasi yang direkomendasikan oleh Final Prediksion Error (FPE), Aike Information Criterion (AIC), Schwarz Criterion (SC) dan Hannan Quinn (HQ). Apabilah terdapat tanda bintang (*) berarti menunjukan Lag optimal.

\section{c. Kointregrasi}

Uji kointegrasi merupakan suatu teknik yang digunakan untuk mengetahui hubungan keseimbangan jangka panjang dari beberapa variabel (Trianto, 2012). Kointegrasi merupakan salah satu metode untuk mengindikasikan kemungkinan adanya hubungan kesetimbangan (equilibrium) jangka panjang antara variabel dependen dan variabel independen (Muhammad, 2014). Untuk mengetahui data tersebut terkointegrasi atau tidak dapat dilihat pada hasil uji Johansen Test yaitu membandingkan nilai Trace dan Max-aigen-nya dengan nilai kritis $1 \%$ dan 5\%. Jika Trace dan Max-aigen > nilai kritis maka data terkointegrasi.

\section{d. Uji Kausalitas Grengar (Granger Causality Test)}

Dalam penelitian ini, variabel JUB, BI Rate dan inflasi apakah ada hubungan timbal balik antara ketiga variabel tersebut. Adapun persamaan Granger Causality (Susiloweti,2016:4) sebagai berikut:

$$
\begin{aligned}
& \mathrm{JUB}_{\mathrm{t}}=\beta_{1}+\sum \beta_{1} J U B_{t-i}+\sum \beta_{1} \text { BI rate }_{t-i}+\sum \beta_{1} I N F_{t-i}+e \\
& \mathrm{BI} \mathrm{rate}_{\mathrm{t}}=\beta_{2}+\sum \beta_{2} J U B_{t-i}+\sum \beta_{2} \text { BI rate }_{t-i}+\sum \beta_{2} I N F_{t-i}+e \\
& \mathrm{INF}_{\mathrm{t}}=\beta_{3}+\sum \beta_{3} J U B_{t-i}+\sum \beta_{3} \text { BI rate }_{t-i}+\sum \beta_{3} I N F_{t-i}+e
\end{aligned}
$$

Keterangan:

$\mathrm{JUB}_{\mathrm{t}}=\mathrm{JUB}$ pada tahun $\mathrm{t}$ 
$\mathrm{JUB}_{\mathrm{t}-\mathrm{I}}=\mathrm{JUB}$ pada tahun sebelumnya ke-i

$\mathrm{BI}$ rate $_{\mathrm{t}}=\mathrm{BI}$ rate pada tahun $\mathrm{t}$

BI rate t-I $=$ BI Rate pada tahun sebelumnya ke-i

$\mathrm{INF}_{\mathrm{t}}=$ Inflasi pada tahun $\mathrm{t}$

$\mathrm{INF}_{\mathrm{t}-\mathrm{I}}=$ Inflasi pada tahun sebelumnya ke-i

$\beta_{1 \mathrm{i}} \quad=$ kostanta

e $\quad=$ Faktor pengganggu

\section{HASIL PENELITIAN DAN PEMBAHASAN}

\section{Uji Stasionaritas (Unit Root Test)}

Uji ini digunakan untuk mengetahui apakah data memiliki unit root atau tidak serta untuk mengetahui derajat stasioneritas data. Uji stasioneritas data dilakukan untuk melihat apakah data terintegrasi pada ordo yang sama atau tidak. Pengujian stasioneritas dalam penelitian ini dilakukan dengan menggunakan uji Augmented Dickey-Fuller (ADF) dan Phillips-Perron (PP). Pengujian ini dilakukan dengan membandingkan antara t-statistic dan critical value $(1 \%, 5 \%, 10 \%)$ yang dihasilkan, apabila t-statistic lebih besar daripada critical value maka H0 di tolak, yang berarti data adalah stasioner (Oktavia dan Amri, 2017:169). Oleh karna itu, stasioner atau tidaknya data JUB dapat dilihat pada Tabel 4.4 berikut:

\section{Tabel 2}

\section{Uji Stasioneritas (Unit RootTest) Pada Data Variabel JUB}

\section{Null Hypothesis: JUB has a unit root}

Exogenous: Constant, Linear Trend

Lag Length: 0 (Automatic - based on SIC, maxlag=11)

t-Statistic Prob.*

\begin{tabular}{lcc} 
Augmented Dickey-Fuller test statistic & -3.783735 & 0.0223 \\
\hline Test critical values: & $1 \%$ level & -4.072415 \\
& $5 \%$ level & -3.464865 \\
& $10 \%$ level & -3.158974 \\
\hline \hline
\end{tabular}

Sumber:Hasil Penelitian (Data diolah:2017)

Berdasarkan hasil pengujian seperti pada Tabel 4.4 di atas, ternyata JUB pada tingkat level tidak stasioner. Karena nilai $\mathrm{ADF}_{\text {statistik }}$ lebih kecil dari test critical valuesnya, baik $1 \%, 5 \%$ dan $10 \%$. Dan nilai probabilitasnya besar $2 \%$. Jika hasil uji stasioneritas berdasarkan uji ADF diperoleh data seluruh variabel belum stasioner pada level, maka untuk memperoleh data yang stasioner dapat dilakukan dengan cara differencing data yaitu dengan mengurangi data tersebut dengan data periode sebelumnya, sehingga akan diperoleh data dalam bentuk first difference. Karena data di atas tidak stasioner maka data akan dikurangi dengan uji first difference yaitu sebagai berikut:

\section{Tabel 3}

\section{Hasil uji First Difference Pada Data JUB}

Null Hypothesis: D(JUB) has a unit root

Exogenous: Constant, Linear Trend

Lag Length: 3 (Automatic - based on SIC, maxlag=11)

t-Statistic Prob.*

Augmented Dickey-Fuller test statistic

$-7.228256 \quad 0.0000$

$\begin{array}{lll}\text { Test critical values: } & 1 \% \text { level } & -4.078420 \\ & 5 \% \text { level } & -3.467703 \\ & 10 \% \text { level } & -3.160627\end{array}$

Sumber:Hasil Penelitian (Data diolah:2017)

Berdasarkan hasil pengujian first difference seperti pada Tabel 4.5 di atas, ternyata JUB pada tingkat level stasioner. Karena nilai

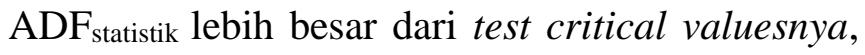
baik $1 \%, 5 \%$ dan $10 \%$. Selain itu juga terlihat bahwa nilai probabilitasnya lebih kecil dari $\alpha=$ 1\%. Selanjutnya adalah melihat stasioner atau tidaknya data BI Rate dapat dilihat pada Tabel 4.6 berikut:

Tabel 4

Uji Stasioneritas (Unit RootTest) Pada Data Variabel BI Rate

Null Hypothesis: BI_RATE has a unit root

Exogenous: Constant, Linear Trend

Lag Length: 0 (Automatic - based on SIC, maxlag=11)

t-Statistic Prob.*

Augmented Dickey-Fuller test statistic $-0.389872 \quad 0.9865$

Test critical values: $1 \%$ level

$-4.072415$ 
$5 \%$ level $\quad-3.464865$

$10 \%$ level

$-3.158974$

Sumber:Hasil Penelitian (Data diolah:2017)

Berdasarkan hasil pengujian seperti pada Tabel 4.6 di atas, ternyata BI Rate pada tingkat level tidak stasioner. Karena nilai $\mathrm{ADF}_{\text {statistik }}$ lebih kecil dari test critical valuesnya, baik $1 \%, 5 \%$ dan $10 \%$. Selain itu juga terlihat bahwa nilai probabilitasnya lebih besar dari $\alpha=10 \%$. Maka perlu melakukan uji first difference yaitu sebagai berikut:

\section{Tabel 5}

\section{Hasil uji First Difference Pada Data} Variabel BI Rate

Null Hypothesis: D(BI_RATE) has a unit root

Exogenous: Constant, Linear Trend

Lag Length: 0 (Automatic - based on SIC, maxlag=11)

t-Statistic Prob.*

Augmented Dickey-Fuller test statistic $-9.331577 \quad 0.0000$

Test critical values:

$1 \%$ level

$-4.073859$

$5 \%$ level

$-3.465548$

$10 \%$ level

$-3.159372$

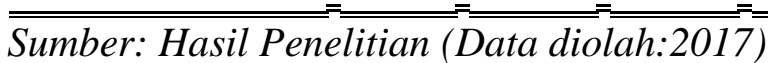

Berdasarkan hasil pengujian first difference seperti pada Tabel 4.7 di atas, ternyata BI Rate pada tingkat level stasioner. Karena nilai

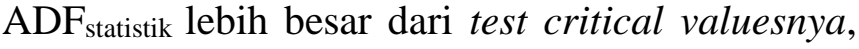
baik $1 \%, 5 \%$ dan $10 \%$. Selain itu juga terlihat bahwa nilai probabilitasnya lebih kecil dari $\alpha=$ $1 \%$. Kemudian melihat stasioner atau tidaknya data inflasi dapat dilihat pada Tabel 4.8 berikut:

\section{Tabel 6}

\section{Uji Stasioneritas (Unit RootTest) Pada Data}

\section{Variabel Inflasi}

Null Hypothesis: INFLASI has a unit root

Exogenous: Constant, Linear Trend

Lag Length: 1 (Automatic - based on SIC, maxlag=11)

t-Statistic Prob.*

\begin{tabular}{lcc} 
Augmented Dickey-Fuller test statistic & -2.524772 & 0.3158 \\
\hline Test critical values: & 1\% level & -4.073859 \\
& 5\% level & -3.465548 \\
& $10 \%$ level & -3.159372 \\
\hline \hline
\end{tabular}

Sumber:Hasil Penelitian (Data diolah:2017)

Berdasarkan hasil pengujian seperti pada Tabel 4.8 di atas, ternyata BI Rate pada tingkat level tidak stasioner. Karena nilai $\mathrm{ADF}_{\text {statistik }}$ lebih kecil dari test critical valuesnya, baik 1\%, 5\% dan $10 \%$. Selain itu juga terlihat bahwa nilai probabilitasnya lebih besar dari $\alpha=10 \%$. Maka perlu melakukan uji first difference yautu sebagai berikut:

\section{Tabel 7}

Hasil uji First Difference Pada Data Variabel Inflasi

Null Hypothesis: D(INFLASI) has a unit root

Exogenous: Constant, Linear Trend

Lag Length: 1 (Automatic - based on SIC, maxlag=11)

t-Statistic Prob.*

\begin{tabular}{lll} 
Augmented Dickey-Fuller test statistic & -6.948548 & 0.0000 \\
\hline Test critical values: & $1 \%$ level & -4.075340 \\
& $5 \%$ level & -3.466248 \\
& $10 \%$ level & -3.159780
\end{tabular}

Sumber:Hasil Penelitian (Data diolah:2017)

Berdasarkan hasil pengujian first difference seperti pada Tabel 4.6 di atas, ternyata Inflasi pada tingkat level stasioner. Karena nilai

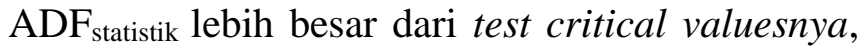
baik $1 \%$, 5\% dan $10 \%$. Selain itu juga terlihat bahwa nilai probabilitasnya lebih kecil dari $\alpha=$ $1 \%$.

\section{Penentuan Lag Optimal}

Dalam menggunakan metode Granger Causality, juga dilakukan penentuan panjang lag yang ada dalam variabel penelitian. Jika panjang lag yang digunakan terlalu banyak lag dalam model, maka dapat mengurangi kemampuan hipotesis nol (H0) ditolak karena tambahan 
parameter yang terlalu banyak akan mengurangi derajat bebas (Maria Alvyonita, 2012:624). Penentuan jumlah lag dalam metode Vector Autore Rression (VAR) ditentukan pada kriteria informasi yang direkomendasikan oleh Final Prediksion Error (FPE), Aike Information Criterion (AIC), Schwarz Criterion (SC) dan Hannan Quinn (HQ). Apabila terdapat tanda bintang (*) berarti menunjukan Lag optimal. Oleh karena itu, Lag Optimal dapat dilihat pada Tabel berikut:

\section{Tabel 8}

\section{Uji Lag Length Criteria}

\begin{tabular}{|c|c|c|c|c|c|c|}
\hline Lag & $\log L$ & LR & FPE & AIC & $\mathrm{SC}$ & HQ \\
\hline 0 & -1287.680 & NA & $7.28 \mathrm{e}+10$ & 33.52417 & 33.61548 & 33.56069 \\
\hline 1 & -1003.687 & 538.4805 & $57548320^{*}$ & $26.38149^{*}$ & $26.74675^{*}$ & $26.52759 *$ \\
\hline 2 & -997.4694 & 11.30504 & 61937133 & 26.45375 & 27.09297 & 26.70943 \\
\hline 3 & -989.7384 & 13.45405 & 64199474 & 26.48671 & 27.39988 & 26.85197 \\
\hline 4 & -987.7392 & 3.323379 & 77416542 & 26.66855 & 27.85567 & 27.14339 \\
\hline 5 & -976.3775 & $18.00164 *$ & 73441472 & 26.60721 & 28.06828 & 27.19162 \\
\hline 6 & -969.4401 & 10.45114 & 78479344 & 26.66078 & 28.39581 & 27.35478 \\
\hline 7 & -964.9729 & 6.381621 & 89877751 & 26.77852 & 28.78749 & 27.58209 \\
\hline
\end{tabular}

Sumber:Hasil Penelitian (Data diolah:2017)

Berdasarkan pada Tabel 4.10 di atas, dapat dilihat bahwa FPE, AIC, SC dan HQ leg optimalnya terdapat pada lag 1.

\section{Kointegrasi}

Tabel 9

Uji Kointegrasi

\begin{tabular}{lllll}
\hline \hline \multicolumn{4}{l}{ Unrestricted Cointegration Rank Test (Trace) } \\
\hline \hline $\begin{array}{l}\text { Hypothesized } \\
\text { No. of CE(s) Eigenvalue }\end{array}$ & $\begin{array}{l}\text { Trace } \\
\text { Statistic }\end{array}$ & $\begin{array}{l}0.05 \\
\text { Critical ValueProb.** }\end{array}$ \\
\hline \hline None * & 0.342290 & 52.79058 & 35.01090 & 0.0003 \\
At most 1 * & 0.201069 & 18.43327 & 18.39771 & 0.0494 \\
At most 2 & 0.000315 & 0.025848 & 3.841466 & 0.8722 \\
\hline \hline
\end{tabular}

Trace test indicates 2 cointegrating eqn(s) at the 0.05 level

* denotes rejection of the hypothesis at the 0.05 level

**MacKinnon-Haug-Michelis (1999) p-values

Unrestricted Cointegration Rank Test (Maximum Eigenvalue)

\begin{tabular}{lllll}
\hline \hline $\begin{array}{l}\text { Hypothesized } \\
\text { No. of CE(s) Eigenvalue }\end{array}$ & $\begin{array}{l}\text { Max-Eigen } \\
\text { Statistic }\end{array}$ & \multicolumn{2}{l}{$\begin{array}{l}\text { C.05 } \\
\text { Critical ValueProb.** }\end{array}$} \\
\hline \hline None * & 0.342290 & 34.35730 & 24.25202 & 0.0017 \\
At most 1* & 0.201069 & 18.40743 & 17.14769 & 0.0327
\end{tabular}

$\begin{array}{lllll}\text { At most } 2 & 0.000315 & 0.025848 & 3.841466 & 0.8722\end{array}$

Max-eigenvalue test indicates 2 cointegrating eqn(s) at the 0.05 level

$*$ denotes rejection of the hypothesis at the 0.05 level

**MacKinnon-Haug-Michelis (1999) p-values

Sumber:Hasil Penelitian (Data diolah:2017)

Berdasarkan tebel di atas, terlihat bahwa nilai Trace Statistic lebih besar dari niai kritis dan nilai Max-Eigen juga menunjukan lebih besar dari nilai kritis $1 \%$ dan 5\%. Oleh karena itu, berdasarkan hasil tersebut maka data dalam penelitian ini terkointegrasi artinya adalah terdapat hubungan jangka panjang antara variabel jumlah penduduk, tingkat suku bunga dan inflasi di Indonesia selama periode penelitian.

\section{Regresi Granger Kausality}

Dalam penelitian ini variabel yang diregres adalah variabel JUB yang di notasikan dengan (X1), BI Rate yang di notasikan dengan (X2) dan inflasi yang di notasikan dengan (X3). Oleh karena itu, hasil regres dalam penelitian ini dapat dilihat pada Tabel berikut:

\section{Tabel 10}

\section{Hasil Regres Granger Kausality}

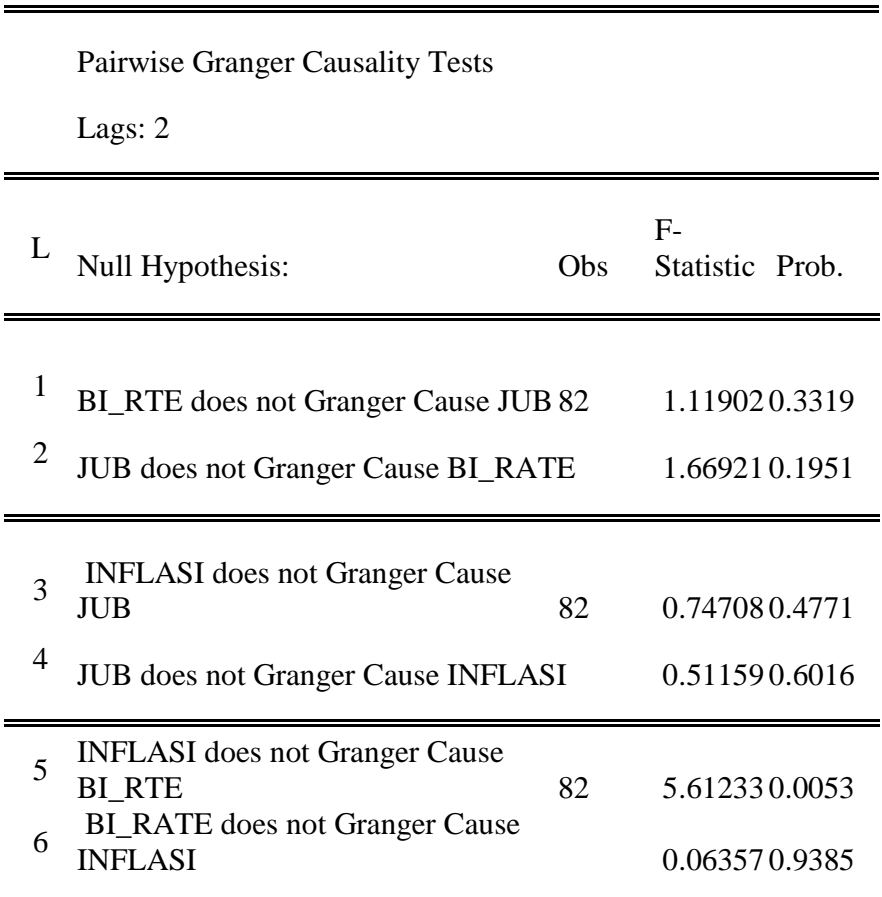

Sumber:Hasil Penelitian (Data diolah:2017)

Berdasarkan hasil uji granger kausalitas pada Tabel di atas, maka dapat disimpulkan bahwa tidak tedapat hubungan antara BI Rate dengan JUB karena nilai probabilitasnya sebesar 0.332 
berarti lebih besar dari $\alpha$ (torenasi) $(1 \%, 5 \%$ dan $10 \%$ ). Sedangkan hubungan JUB dengan BI Rate juga menunjukan tidak terdapat hubungan antara kedua variabel tersebut karena nilai probabilitasnya lebih besar dari $\alpha$ (toleransi). Selanjutnya hubungan antara inflasi dengan jumlah JUB juga tidak terdapat hungan kausalitas antara kedua variabel tersebut karena nilai probabilitasnya lebih besar dari $\alpha$ (torenasi) (1\%, $5 \%$ dan $10 \%$ ). Kemudian terdapat hubungan antara inflasi dengan BI Rate karena nilai probabilitasnya sebesar 0,053 maka lebih kecil dari $\alpha$ (torenasi) (10\%). Sedangkan hubungan antara inflasi dengan BI Rate tidak terdapat hubungan antara kedua variabel tersebut, karena nilai probabilitasnya lebih besar dari $\alpha$ (torenasi) $(1 \%, 5 \%$ dan 10\%).

\section{Pembahasan}

\section{Hubungan Kausalitas Antara JUB Dengan BI Rate}

Berdasarkan hasil penelitian diatas dapat diambil kesimpulan bahwa $\mathrm{H}_{1}$ ditolak dan terima Ho1 maka tidak terdapat hubungan kausalitas antara JUB dengan BI Rate baik hubungan dua arah maupun satu arah. Hal ini dapat di lihat pada nilai probabilitasnya yaitu sebesar 0.195 dan sebaliknya, BI Rate dengan JUB nilai probabilitasnya sebesar 0,332 berarti lebih besar dari nilai $\alpha$ (torenasi) $(1 \%, 5 \%$ dan $10 \%)$. Bererti bahwa variabel JUB dan BI Rate sama-sama tidak saling mempengaruhi antara satu dengan lainnya, artinya JUB tidak mempengaruhi BI Rate dan BI Rate tidak pula mempengaruhi JUB. Hal ini menunjukan bahwa di laksanakan (realisasi) kebijakan menaikkan atau menurunkan BI Rate yang dilakukan oleh Bank Indonesia (BI) memiliki jangka waktu dan tidak bisa dengan cepat mempengaruhi JUB yang ada, dan begitu juga sebaliknya. Pada periode penelitian ini terjadi fenomena baru dari penelitian-penelitian terdahulu.

Oleh karena itu hasil penelitian ini yang penulis lakukan tidak sejalan dengan hasil penelitian yang di lakukan oleh (Akbar, 2012), hasil penelitiannya menunjukan bahwa terdapat hubungan negatif dan signifikan antara penawaran uang dengan BI Rate. Artinya adalah meningkatnya JUB dapat mendorong turunnya BI
Rate. Kemudian, jika BI Rate tinggi masyarakat akan cendrung menabung uangnya di bank. Hal ini diikuti dengan berkurangnya jumlah uang yang beredar, keinginan masyarakat untuk melakukan pembelanjaan pun akan menurun. Ini artinya kenaikan dalam penawaran uang akan menyebabkan turunnya BI Rate, dan sebaliknya.

\section{Hubungan Kausalitas Antara JUB Dengan Inflasi}

Berdasarkan hasil penelitian pada tabel di atas maka $\mathrm{H}_{2}$ ditolak dan terima $\mathrm{H}_{\mathrm{O} 2}$ berarti tidak terdapat hubungan kausalitas antara JUB dengan inflasi karena nilai probabilitasnya lebih besar dari $\alpha$ (torenasi) $(1 \%, 5 \%$ dan 10\%). Bererti bahwa variabel JUB dengan inflasi sama-sama tidak saling mempengaruhi antara satu dengan lainnya, artinya JUB tidak mempengaruhi inflasi dan inflasi tidak pula mempengaruhi JUB. Artiya adalah perubahan JUB di masyarakat akibat kebijakan moneter yang di lakukan oleh Bank Indonesia (BI) tidak lansung mempengaruhi inflasi secara cepat, tetapi memerlukan waktu jangka panjang dan begitu pula sebaliknya yaitu hubungan inflasi dengan JUB.

Kesimpulannya adalah selama periode penelitian yang penulis lakukan memperoleh fenomena baru sehingga tidak sejalan dengan hasil penelitian yang di lakukan (Setyawan, 2005), hasil penelitiannya adalah dalam periode tersebut terdapat hubungan kausalitas satu arah antara kedua variabel tersebut yaitu perubahan JUB akan mempengaruhi tingkat inflasi di Indonesia dan bukan sebaliknya.

\section{Hubungan Kausalitas BI Rate Dengan Inflasi}

Dari tabel regresi granger causality di atas berarti $\mathrm{H}_{03}$ ditolak dan terima $\mathrm{H}_{3}$ maka dapat di ketahui bahwa terdapat hubungan satu arah antara kedua variabel tersebut Artinya adalah hanya variabel inflasi yang mempengaruhi BI Rate yang di tunjukan oleh nilai probabilitasnya sebesar 0,005 bererti lebih kecil dari nilai $\alpha$. Sedangkan BI Rate tidak mempengaruhi inflasi karena nilai probabilitasnya lebih besar dari $\alpha$ (torenasi) $(1 \%$, $5 \%$ dan 10\%). Dari hasil penelitian ini berarti perubahan tingkat inflasi dapat mempengaruhi BI Rate dan bukan sebaliknya yaitu perubahan BI Rate tidak mempengaruhi tingkat inflasi secara 
cepat dan harus memiliki waktu jangka panjang. Hal ini di sebabkan karena BI telah memberlakukan BI 7- Day Repo Rate sebagai acuan bukan lagi BI rate. Hasil penelitian ini sejalan dengan hasil penelitian yang dilakukan oleh (Setioeti, 2014), yang berjudul "Analisis Hubungan Kausalitas Antara BI Rate Dengan Inflasi Di Indonesia Periode Juli 2006 - Juli 2013. hasil penelitian menunjukan bahwa terdapat hubungan satu arah pada uji kausalitas Granger yaitu perubahan inflasi menyebabkan perubahan BI Rate dan bukan sebaliknya.

\section{KESIMPULAN DAN SARAN Kesimpulan}

Berdasarkan rumusan masalah dan hasil penelitian maka penulis mengambil kesimpulan yaitu sebagai berikut:

1. Hubungan jumlah penduduk deangan BI Rate

Tidak terdapat hubungan kausalitas antara JUB dengan BI Rate. Hal ini dapat di lihat pada nilai probabilitasnya yaitu sebesar 0.195 dan sebaliknya, BI Rate dengan JUB nilai probabilitasnya sebesar 0,332 berarti lebih besar dari $\alpha$ (torenasi) $(1 \%, 5 \%$ dan 10\%). Bererti bahwa variabel JUB dan BI Rate sama-sama tidak saling mempengaruhi antara satu dengan lainnya, artinya JUB tidak mempengaruhi BI Rate dan BI Rate tidak pula mempengaruhi JUB.

\section{Hubungan JUB dengan inflasi}

Tidak ada hubungan kausalitas antara JUB dengan inflasi karena nilai probabilitasnya lebih besar dari $\alpha$ (torenasi) $(1 \%, 5 \%$ dan $10 \%)$. Bererti bahwa variabel JUB dengan inflasi sama-sama tidak saling mempengaruhi antara satu dengan lainnya, artinya JUB tidak mempengaruhi inflasi dan tidak pula mempengaruhi JUB.

3. Hubungan BI Rate dengan inflasi

Terdapat hubungan satu arah antara BI Rate dengan inflasi Artinya adalah hanya variabel inflasi yang mempengaruhi BI Rate yang di tunjukan oleh nilai probabilitasnya sebesar 0,005 bererti lebih kecil dari nilai $\alpha$. Sedangkan BI Rate tidak mempengaruhi inflasi karena nilai probabilitasnya lebih besar dari $\alpha$ (torenasi) (1\%, $5 \%$ dan $10 \%$ ).
Saran

Berdasarkan hasil dan kesimpulan penelitian di atas, maka penulis merumuskan beberapa saran sebagai berikut:

1. Untuk Bank Indonesia agar dapat berkoordinasi dengan pemerintah dalam mencermati perkembangan perekonomian regional, domestik dan perospek perekonomian global agar perekonomian Indonesia selalu stabil. Pemerintah dan Bank Indonesia harus lebih teliti dalam menentukan kebijakannya untuk mengendalikan JUB, BI Rate dan laju inflasi.

2. Untuk peneliti selanjutnya agar menambah variabel penelitian yang tidak terdapat dalam penelitian ini dengan tujuan agar kita dapat mengetahui hubungan kausalitas variabel lain dengan variabel dalam penelitian ini.

\section{DAFTAR PUSTAKA}

Akbar, D. A. (2012). Kausalitas Inflasi, Tingkat Suku Bunga, dan Jumlah Uang Beredar : A Case of Indonesia Economy. Jurnal Ilmiah STIE MDP, 2(1), 59-68.

Bank Indonesia. 2011. Inflasi Diakses dari Bank

Indonesia website: http://www.BI.go.id .2004. Bank Indonesia, Bank Sentral Republik Indonesia.

Hidayat, P. (2013). Analisis Kausalitas Dan Kointegrasi Antara Tingkat Suku Bunga Bank Indonesia (Bi Rate) Dengan Suku Bunga Bank Amerika Serikat (The Fed). Jurnal Ekonomi Dan Keuangan Vol. 1 No. $8,(2009)$.

Maria Alvyonita, P. H. (2012). Analisis Kausalitas Antara Bi Rate Dengan Jumlah Uang Beredar Di Indonesia. Jurnal Ekonomi Dan Keuangan vol.2 No.10, (1999), 623-633.

Muhammad, M. (2014). Kointegrasi dan estimasi ecm pada data time series, 4(1), 41-51.

Mursalin. (2016). Pengaruh Jumlah Uang Beredar Dan Jumlah Penduduk Terhadap Pertumbuhan Ekonomi Di Kota Lhokseumawe Tahun 2006-2013. 
Niki Ermija Oktavia dan Amri. (2017). Analisis

Kausalitas Antara Inflasi Dan Konsumsi

Di Indonesia. Jurnal Ilmiah Mahasiswa (JIM) Ekonomi Pembangunan Fakultas Ekonomi Dan Bisnis Unsyiah Vol.2 No.1 Februari 2017: 164- 175, 2(1), 164-175.

Qizfir. (2015). Pengaruh Tingkat Suku Bunga, Inflasi Dan Return On Asset Terhadap Kredit Macet Di Bank Aceh.

Setioeti, L. (2014). Analisis Hubungan Kausalitas Antara Bi Rate Dengan Inflasi Di Indonesia Periode Juli 2006Juli 2013 Menggunakan Metode Granger Dan Final Prediction Error.

Setyawan, A. B. (2005). Kausalitas Jumlah Uang Beredar Dan Inflasi ( Sebuah Kajian Ulang ), 23-24.

Silvanita, K. (2009). Bank Dan Lembaga Keuangan Lainnya. Jakarta: penerbit Erlangga.

Trianto, D. W. (2012). Uji Kointegrasi Dengan Metode Johansen Dan Aplikasinya Pada Data Harga Sembako Di Pasar Induk Kota Yogyakarta (Studi Kasus : Data Harga Daging Sapi Dan Daging Ayam Kampung), 2-4.

Yodiatmaja, B. (2012). Hubungan antara bi rate dan inflasi pendekatan kausalitas toda yamamoto. Journal of Economics and Policy, 5(2), 127-136. 